\title{
Characterization of petroleum-based plastics and their absorbed trace metals from the sediments of the Marina Beach in Chennai, India
}

Thodhal Yoganandham Suman ${ }^{1,2,3 \dagger}$, Wei-Guo Li ${ }^{1 \dagger}$, Shaji Alif ${ }^{4}$, Valappil Rahman Panangala Faris ${ }^{4}$, Duvvuru Joshua Amarnath ${ }^{4}$, Jun-Guo Ma ${ }^{1}$ and De-Sheng Pei ${ }^{1,2^{*}}$ (i)

\begin{abstract}
Background: Pollution by marine plastic debris becomes an increasing global concern. Characteristics of petroleumbased plastics pollution and its absorbed metals in Marina Beach, Chennai, in India are not reported yet. In this study, we first characterized the petroleum-based plastic debris and quantified the concentration of arsenic (As), chromium $(\mathrm{Cr})$, copper $(\mathrm{Cu})$, and lead $(\mathrm{Pb})$ in plastics from the Marina Beach.

Results: A total of 2275 samples of the sediments were collected from three different locations across the Marina Beach. Our results showed that plastics debris mainly were three shapes as fiber, sphere, and fragment. The plastic fragments were mechanically eroded and chemically weathered observed by the scanning electron microscope (SEM). Five types of polymers were identified, including low-density polyethylene (LDPE), polyethylene terephthalate (PET), polypropylene (PP), polyamide (PA), and polycarbonate (PC). Their absorbed trace metals, such as $\mathrm{Cr}, \mathrm{As}, \mathrm{Pb}$, and $\mathrm{Cu}$, were determined by the inductively coupled plasma mass spectrometry (ICP-MS). The level of As was high in most plastics. However, the highest levels of $\mathrm{Pb}, \mathrm{Cu}$, and $\mathrm{Cr}$ were in the PA, PP, and PA, respectively, implying the adsorption preference of plastics from different sources.

Conclusion: Taken together, this study first characterized petroleum-based plastics and their absorbed trace metals in the sediments of the Marina Beach, indicating that petroleum-based plastics acted as the vectors for the transportation of metal elements in the marine biome.
\end{abstract}

Keywords: Plastic, Marina Beach, Chennai, Trace metal, Vector

\section{Background}

Petroleum-based plastics are artificial organic polymers, obtained from natural gas or oil, and utilized in contemporary society in every aspect of daily life [1-3]. Global petroleum-based plastic production in

\footnotetext{
*Correspondence: peids@cigit.ac.cn

†'Suman Thodhal Yoganandham and Wei-Guo Li contributed equally to the manuscript

${ }^{1}$ College of Life Science, Henan Normal University, Xinxiang 453007,

Henan, China

Full list of author information is available at the end of the article
}

2015 reached 322 million tons, while in 1950, the production was 1.7 million tons [4]. During the twentieth century urbanization in the vicinity of coastal environments, the utilization of petroleum-based plastic materials in the various applications, especially in the medicinal, industrial area, commercial, and municipal field, has steadily increased and unknowingly or knowingly released into the environment, which leads to a significant environmental problem [5-8]. Petroleumbased plastics may be fragmented, but cannot naturally break down due to their profound stability [9]. Even the

\section{Springer Open}

(c) The Author(s) 2020. This article is licensed under a Creative Commons Attribution 4.0 International License, which permits use, sharing, adaptation, distribution and reproduction in any medium or format, as long as you give appropriate credit to the original author(s) and the source, provide a link to the Creative Commons licence, and indicate if changes were made. The images or other third party material in this article are included in the article's Creative Commons licence, unless indicated otherwise in a credit line to the material. If material is not included in the article's Creative Commons licence and your intended use is not permitted by statutory regulation or exceeds the permitted use, you will need to obtain permission directly from the copyright holder. To view a copy of this licence, visit http://creativeco mmons.org/licenses/by/4.0/. 
degradable plastic materials can last for many years, depending on environmental circumstances, such as temperature, oxygen, and the exposure levels of ultraviolet (UV) light [10]. Also, stabilizers and plasticizers are included to enhance the characteristics features and efficiency of petroleum-based plastic materials [11], and during the degradation process, they may be leaked into the environmental system [12].

Generally, the term plastics are referred to larger sized plastic materials ranging from $2.5 \mathrm{~cm}$ to $1 \mathrm{~m}$ of known items, such as bottles, large containers, plastic toys, and buoys. The term mesoplastics are generally referred to as the size of particles from $5 \mathrm{~mm}$ to $2.5 \mathrm{~cm} \mathrm{[13].} \mathrm{Vari-}$ ous researchers have faced practical categories in dividing small plastics $(0.1-1 \mathrm{~mm})$ and abundant plastics (1-5 mm) [14]. The primary microplastics are produced in microsize, and the secondary microplastics are generated by disintegrating larger plastic materials to smaller plastic fragments [3]. The accumulation of large plastic debris in the marine ecosystem is because of the severe discharge of plastic-based materials [15], albeit some of the waste plastics are appropriately done by burning or recycling. In 2010, around 4.8 to 12.7 million metric tons of plastics were released into the marine biome [16].

After the plastic debris is thrown out into beaches, it will absorb metals from the surrounding environment [17-22]. The toxic effect may happen when the organism is exposed [23]. Rare studies of a petroleum-based plastic accumulation from the beach sediment in India were carried out [24-26]. Several studies have already shown that organic pollutants are absorbed in plastic debris [14, 27]. Recently, the existence of metals on plastic waste was reported [17, 18, 28]. Thus, the plastic fragments act as stressing agents to the organisms, causing adverse effects after consumption [20].

India is among the world's largest consumers of petroleum-based plastics, which can produce about 5.6 million tons of plastic material annually [29]. Chennai is the capital of Tamil Nadu, located in the south-eastern coastal line of India, $56 \mathrm{~km}$ along the coast, which is the fourth most crowded metropolitan city in India [21]. Each year, monsoon carries plastic fragments from the waste piles into the lakes, streams, and rivers, eventually to the beach. Because of human activities, petroleum-based plastics are accumulating on the coastal line, reducing the esthetic attraction, and damaging natural life [1]. The main feasible steps to minimize the environmental impact of petroleum-based plastics are mainly through recovery, treatment, recycling [2]. The qualitative and quantitative study of plastic debris is used to define basic needs for the management of the most plastic waste. By adequately managing anthropogenic waste, economic and ecological effects on marine biomes could be eased
[30]. This study first characterized petroleum-based plastics through the coastline of the Marina Beach according to the size, shape, and color, and quantified their absorbed trace metals including $\mathrm{As}, \mathrm{Cr}, \mathrm{Cu}$, and $\mathrm{Pb}$.

\section{Materials and methods Study area and sampling}

Marina beach is $6 \mathrm{~km}$ long and $300 \mathrm{~m}$ wide, which is one of the busy beaches that draws about 30,000 tourists a day on weekdays and 50,000 on weekends and holidays [31]. This study was conducted at three sites: (1) S1: Lighthouse (13.039687 $\left.{ }^{\circ} \mathrm{N}, 80.279378^{\circ} \mathrm{E}\right)$; (2) S2: Thiruvalluvar statue $\left(13.054669^{\circ} \mathrm{N}, 80.282343^{\circ} \mathrm{E}\right)$; (3) S3: MGR memorial $\left(13.064330^{\circ} \mathrm{N}, 80.285322^{\circ} \mathrm{E}\right)$ in the Marina Beach littoral zone (Additional file 1: Fig. S1). From December 1 to December 4, 2017, all samples were collected. Three different locations were chosen at intervals of about $2 \mathrm{~km}$. Measurements were carried out for each location using quadrates $5 \mathrm{~m}$ in width and $100 \mathrm{~m}$ in length between the high tide and the vegetation line according to the previous study [32]. At each site, three replicates samples were collected. The debris and $5 \mathrm{~cm}$ of sand from each site in the quadrats were sieved as described [24, 33, 34]. Plastic debris and natural particles on sieves were placed in zipper bags and transported to the laboratory for the subsequent study.

\section{The optical microscopy analysis}

All the samples were observed under microscopic observations carried out using Leica Model SZH10, Japan, 4. Plastic debris was classified by shape and color. The same color and shape plastics were known as the same type [35]. The size of the plastic debris was then measured. The measurements of each irregular fragment by the longest length measured using image processing software. After sorting the samples, plastics were thoroughly washed in deionized water using the ultrasonic bath to eliminate tarry residues and sand, dried at $60^{\circ} \mathrm{C}$ for $12 \mathrm{~h}$. The samples were stored at ambient room temperature conditions for further analysis.

\section{The SEM analysis}

Five samples of each form of plastics were analyzed using the SEM to understand the surface characteristics of the plastic debris. Samples were fixed on the aluminum SEM stubs on the dual-sided carbon adhesive tabs according to the previous description [36], and were further sputtered with a thin film using the MCM-100P gold coating unit. The film's coating thickness was, on average, $10 \mathrm{~nm}$ at 8 to $10 \mathrm{~Pa}$ vacuum speeds. Samples were studied at an accelerating voltage of $10 \mathrm{kV}$ using SEM (Carl Zeiss). 
Fourier transform infrared spectroscopy-attenuated total reflectance (ATR-FTIR) and thermogravimetry-differential scanning calorimetry (TGA-DSC)

The polymer composition of 20 components with each shape was identified using the ATR-FTIR technique and TGA-DSC method. The most accurate technique for the identification of plastic chemical composition was infrared spectroscopy $[37,38]$. ATR-FTIR was used to analyze plastics. The plastic debris was analyzed using the FTIR spectrometer with a DTGS detector on a Jasco 4700 spectrum. The wavelength ranging from 4000 to $600 \mathrm{~cm}^{-1}$, and 16 scans per sample were conducted at a resolution of $4.0 \mathrm{~cm}^{-1}$. The OPUS 7.5 software was used to compare the polymer spectrum from the database of the most typical polymer and natural material.

A STA6000 (Perkin Elmer) was used to measure TGADSC with a flow rate of $20 \mathrm{~mL} \mathrm{~min}^{-1}$. The heating rate at $10{ }^{\circ} \mathrm{C} \mathrm{min}{ }^{-1}$ with different temperatures was set for dynamic step interruption. The sample was heated in the inert nitrogen atmosphere ranging from 20 to $800{ }^{\circ} \mathrm{C}$ with $5 \mathrm{~K} \mathrm{~min}^{-1}$ to suppress oxidation. At $20{ }^{\circ} \mathrm{C}$ gradient, the measurement was started.

\section{Analysis of metal concentration in the plastic debris}

About 1 g plastic items from each polymer compositions were selected and put into the Teflon microwave digestion tube, and $5 \mathrm{~mL}$ of concentrated supra-pure nitric acid was added $[39,40]$. The vessels of Teflon were assembled, and the acid digestion step was carried out for $50 \mathrm{~min}$. Teflon vessels were placed into Mars 6 microwave digester. The temperature template was set around for $20 \mathrm{~min}$ at $200{ }^{\circ} \mathrm{C}$, the hold temperature at $200{ }^{\circ} \mathrm{C}$ for $15 \mathrm{~min}$, and $15 \mathrm{~min}$ for cooling. Once the digestion was completed, the digested sample was transferred into a $50-\mathrm{mL}$ polyethylene centrifugal vial.

Analyses of $\mathrm{As}, \mathrm{Cr}, \mathrm{Cu}$, and $\mathrm{Pb}$ were performed using the ICP-MS (7700 x, Agilent, USA); to maintain inert condition helium gas was induced inside the collision reaction cell. Radiofrequency mainly focused on the ions and later reacted and collided with collision reaction gas. The helium mode was used to filter all spectral interferences including unidentified and discrete sample matrices. The ICP-MS was calibrated using internal standardization achieved by the addition of ${ }^{45}$ scandium, ${ }^{72}$ germanium, ${ }^{115}$ indium, and ${ }^{209}$ bismuth. The operation conditions for the instrument RF power 1400 is with nebulizer gas $0.30 \mathrm{~L} \mathrm{~min}^{-1}$, inert gas argon $15 \mathrm{~L} \mathrm{~min}^{-1}$, uptake of samples at the rate of $0.3 \mathrm{~mL} \mathrm{~min}^{-1}$. Samples were analyzed through 100 scans per repeat, and 3 repeats per sample were conducted [41]. The detection limit of the instrumental was $1.7 \mathrm{ppt}$ for $\mathrm{Cu}, 4.3 \mathrm{ppt}$ for $\mathrm{Cr}, 1.3 \mathrm{ppt}$ for $\mathrm{Pb}$, and 11.9 ppt for As, respectively.

\section{Statistical analysis}

The data were analyzed using the XLSTAT software (Addinsoft, USA, 2019) and analyzed on the confidence level with Tukey (HSD) test. The values were indicated as the mean \pm standard error (SEM) of the replicates in each group. The multivariate analysis, including principal component analysis (PCA), was performed for data analysis.
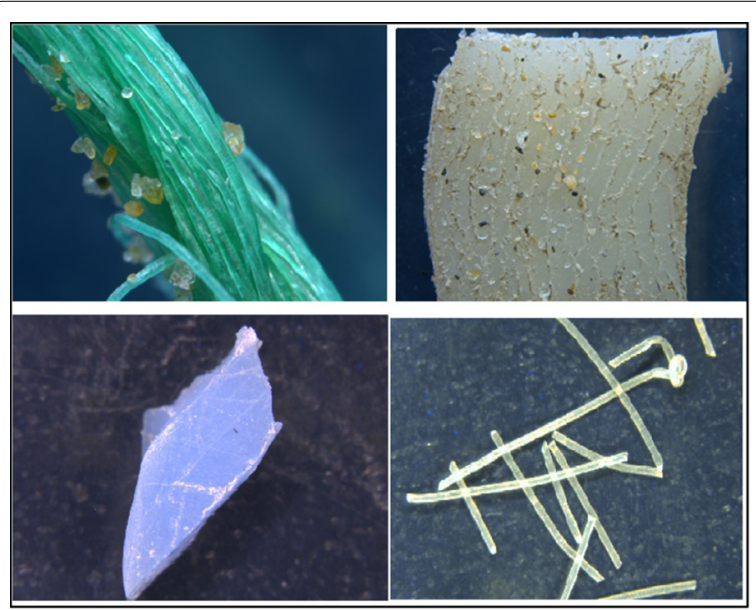

a

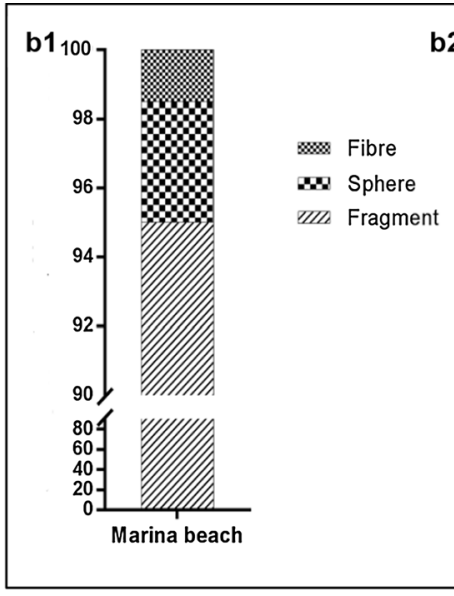

b

Fig. 1 The shape and color distribution of petroleum-based plastics in this study. a Representative images of unwashed petroleum-based plastic debris from the sediment samples from the Marina Beach, Chennai, India. b The shape and color distributions of petroleum-based plastic debris on the Marina Beach 

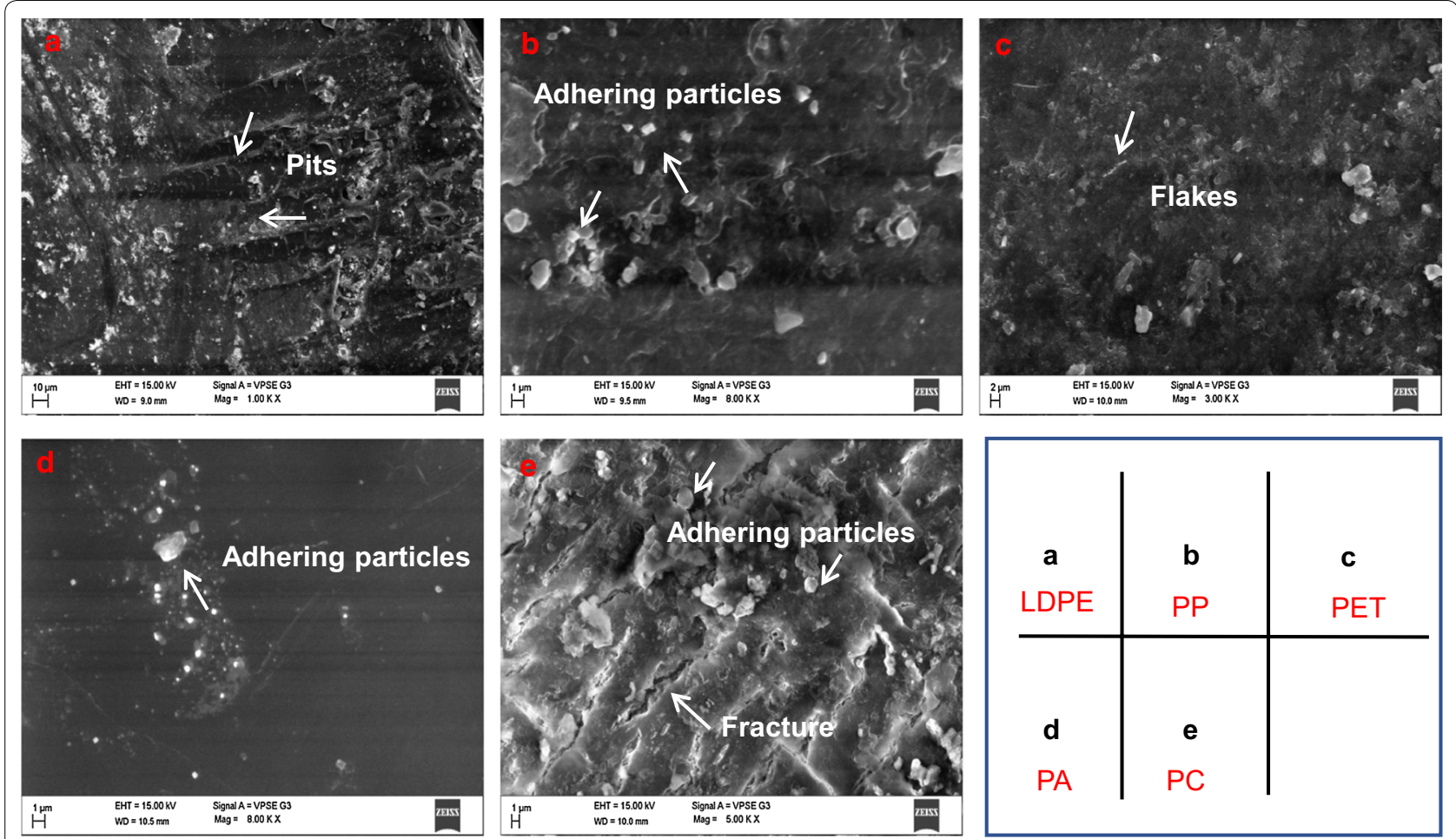

Fig. 2 The texture of chosen petroleum-based plastics. a Pits on the LDPE fragment; $\mathbf{b}$ adhering particles on PP fragment; $\mathbf{c}$ flakes on PET; $\mathbf{d}$ early degradation site and adhering particles on a PA; e adhering particles on PC

\section{Results}

\section{Shape, color, and size of petroleum-based plastic}

Plastic debris with three shapes were identified as fiber, sphere, and fragment (Fig. 1). There were significantly different plastic debris numbers between sampling stations. The Lighthouse and Thiruvalluvar Statue had the highest (830 items) and lowest (636 items) total numbers of plastics debris (Additional file 1: Fig. S2A and Tables $\mathrm{S} 1, \mathrm{~S} 2$ ). Overall, the size of the plastic ranged from 5.5 to $25 \mathrm{~mm}$ (Additional file 1: Fig. S2B). The most found was fragment with about $95 \%$, followed by sphere (3.5) and fiber (1.5), respectively (Fig. 1b1). As shown in (Fig. 1b2), $90 \%$ of the total plastic was white; the other color is yellow, green, red, and blue. There was significant weathering of the plastic debris.

\section{Surface texture and aging status of petroleum-based plastics}

The result of the SEM images showed that the mechanical erosion and chemical weathering were found in the samples collected in the surface sediments of Marina Beach. Pits, adhering, and flakes were the usual pattern of degradation of plastics (Fig. 2a-e), which was confined to mechanical abrasions through adhering particles and grinding of sand. Besides mechanically created pits and fractures, additives used in plastics, such as colorants, fillers, stabilizing materials, and softeners, should have provided an intended area for degradation to begin (Fig. 2a-e). Particles with flakes were available locally for foreign objects to become accommodated, thereby making it possible for the polymer to mechanical degradation (Fig. 2b, d, e).

\section{Composition characterization using the ATR-FTIR and TGA-DSC}

As shown in Fig. 3, plastic particles of LDPE, PP, PET, PA, and PC were detected using ATR-FTIR, and TGADSC. For the LDPE analysis, the strong asymmetric $\mathrm{CH}_{2}$ stretch of $2913-2911 \mathrm{~cm}^{-1}$, the symmetric $\mathrm{CH}_{2}$ stretch of $2847 \mathrm{~cm}^{-1}$, and the symmetric deformation of $\mathrm{CH}_{3}$ were the characteristic spectra of LDPE (Fig. 3a, left panel). There were three bands assigned to $\mathrm{CH}_{2}$ and $\mathrm{CH}_{3}$ groups: a band $\mathrm{I}$ at $1370 \mathrm{~cm}^{-1}$. The thermal stability of plastic debris showed the degradation in a single-step process, and the abundant temperature for decomposition was about $478^{\circ} \mathrm{C}$ for LDPE. DSC results showed that the melting point $(\mathrm{Tm})$ of LDPE is $122^{\circ} \mathrm{C}$ (Fig. 3a, right panel).

For the PP analysis, the absorbance spectra were shown at $2950 \mathrm{~cm}^{-1}, 1455 \mathrm{~cm}^{-1}$, and $1371 \mathrm{~cm}^{-1}$. In the spectrum, the moderate absorption peaks occurred in the 


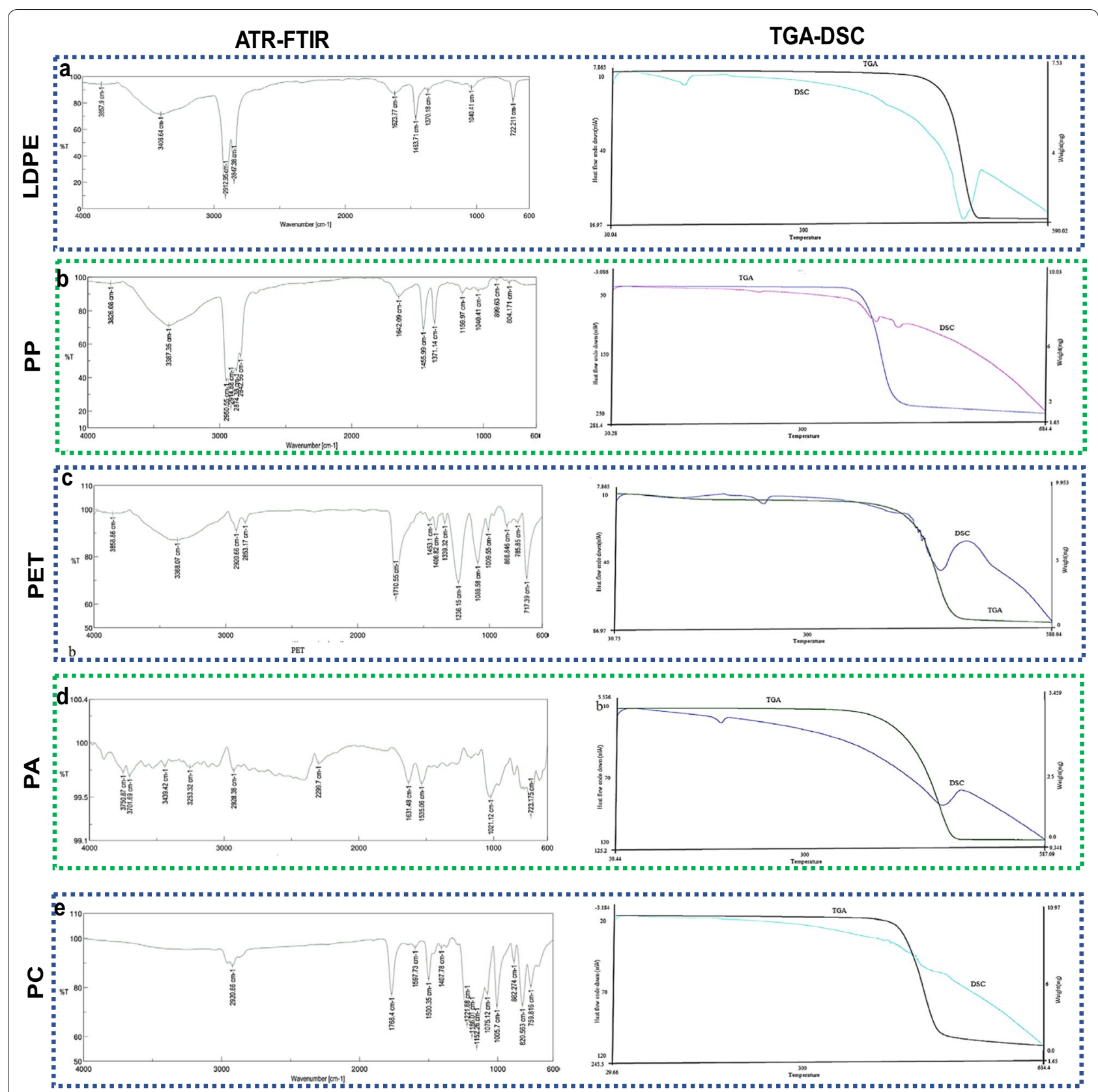

Fig. 3 Characterization of LDPE, PP, PET, PA, and PC using ATR-FTIR and TGA-DSC. The polymer composition of LDPE, PP, PET, PA, and PC plastics debris was characterized using ATR-FTIR, and the peaks of LDPE, PP, PET, PA, and PC were determined by the TGA and DSC under nitrogen atmosphere

spectral band of $1445 \mathrm{~cm}^{-1}$ and $1371 \mathrm{~cm}^{-1}$. The absorption characteristics of 804 and $1001 \mathrm{~cm}^{-1}$ were the typical vibrations of terminal unsaturated $\mathrm{CH}_{2}$ groups in isotactic PP (Fig. 3b).

For the PET analysis, the spectra of PET spectra showed a substantial intensity at $1710 \mathrm{~cm}^{-1}$, which was assigned as $(\mathrm{C}=\mathrm{O})$ stretching carbonyl bonds. The peaks at 1406,866 , and $717 \mathrm{~cm}^{-1}$ were the bonds of $(\mathrm{C}=\mathrm{C})$,
$(=\mathrm{C}-\mathrm{H})$, and $(\mathrm{C}-\mathrm{H})$ detected by stretching vibrations. The vibrational bands $1339 \mathrm{~cm}^{-1}, 1236,1089$, and $1009 \mathrm{~cm}^{-1}$ were assigned to $\mathrm{C}-\mathrm{H}$ and $\mathrm{C}-\mathrm{O}$ stretching vibration (Fig. 3c). The PET is thermally stable and can be decomposed at a maximum temperature of about $445.18^{\circ}$ $\mathrm{C}$ in a single cycle. The DSC results in Fig. 3c suggested that the melting point $(\mathrm{Tm})$ of PET was $219.64{ }^{\circ} \mathrm{C}$. 


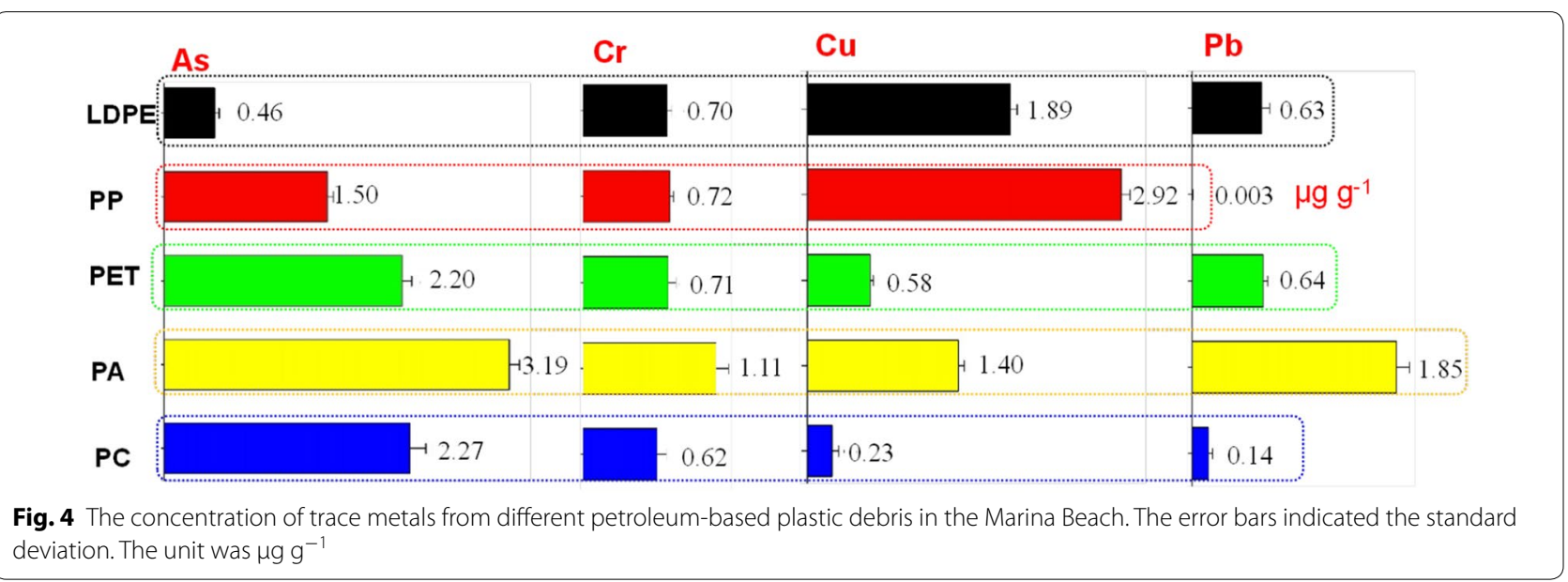

For the PA analysis, $\mathrm{CH}_{2}$ was symmetrically extended, but detected an asymmetric site at $2928 \mathrm{~cm}^{-1}$ with $\mathrm{CH}_{2}$ group vibrations in the polymer chain. The $\mathrm{C}=\mathrm{O}$ stretching was related to the spectrum at $1631.48 \mathrm{~cm}^{-1}$, but there was a spectrum at $1535 \mathrm{~cm}^{-1}$ due to the $\mathrm{N}-\mathrm{H}$ band combination (Fig. 3d, left panel). The thermal stability of PA plastic debris showed the degradation in a singlestep process, and the maximum temperature for decomposition was $455.18^{\circ} \mathrm{C}$ (Fig. 3d, left panel). DSC results showed that the melting point (Tm) of PA was $165.64{ }^{\circ} \mathrm{C}$ (Fig. 3d, right panel).

For PC analysis, the ATR-FTIR spectrum showed the vibration at $2920 \mathrm{~cm}^{-1}$ and $1768.4 \mathrm{~cm}^{-1}$ indicated an aromatic $(\mathrm{C}-\mathrm{H})$ and a strong intensity of carbonyl bonds $\mathrm{C}=\mathrm{O}$ (Fig. 3e, left panel). The thermal stability of plastic debris PC showed the degradation in a single-step process, and the intended temperature for decomposition was found to be $560{ }^{\circ} \mathrm{C}$ (Fig. 3e, right panel). The results of DSC showed that the melting point (Tm) of polycarbonate was $391{ }^{\circ} \mathrm{C}$ (Fig. 3e, right panel).

The absorption pattern of trace metals in the plastic debris In this study, the trace metal concentration of plastic debris collected from the Marina Beach is shown in Fig. 4 and Additional file 1: Table S1. The concentrations of As ranged from $3.19 \pm 0.09$ to $0.46 \pm 0.06 \mu \mathrm{g} \mathrm{g}{ }^{-1}$, with the maximum in the PA and the minimum in the LDP. For the ANOVA and Tukey test, the level of As was different in plastic debris $(p=0.05)$ (Fig. 4, Additional file 1: Fig. S3A and Table S3). The Cr level ranged from $1.11 \pm 0.155$ to $0.62 \pm 0.106 \mu \mathrm{g} \mathrm{g}^{-1}$ with the maximum in the PA and the minimum in the PC. However, the levels of $\mathrm{Cr}$ were identical between polymers except for PA, according to ANOVA and Tukey's test $(p=0.05)$ (Additional file 1: Fig. S3B and Table S4). The level of $\mathrm{Cu}$ in the polymers ranged from $2.92 \pm 0.190$ to $0.23 \pm 0.084 \mu \mathrm{g} \mathrm{g}^{-1}$ with the

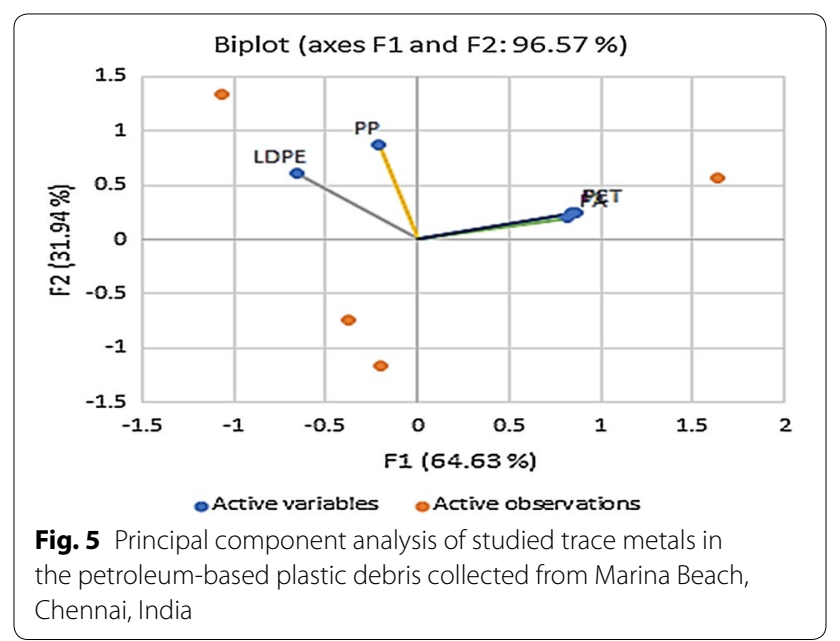

maximum content in the $\mathrm{PP}$ and the minimum content in the PC. The difference of $\mathrm{Cu}$ levels was significant (Additional file 1: Additional file 1: Fig. S3C and Table S5). The levels of $\mathrm{Pb}$ among polymers ranged from $0.14 \pm 0.070$ to $1.85 \pm 0.219 \mu \mathrm{g} \mathrm{g}^{-1}$ with the maximum content in the $\mathrm{PA}$ and the minimum content in the $\mathrm{PC}$, which varied dramatically according to the ANOVA and Tukey tests (Additional file 1: Fig. S3D and Table S6).

To determine the difference between metals in plastic debris, the principal components analysis was performed to describe the principal components of primary metal among plastic types. Additional file 1: Table S7 summarizes the results of PCA for each factor. Two principal components with eigenvalues $>1$ were taken into consideration. PC1 contributed to $64.63 \%$ variance with the highest eigenvalue 3.231, having the loading in As $(R=2.549)$. The result of PC2 elucidated $31.94 \%$ of the total difference with the highest loading of $\mathrm{Cu}(R=1.463)$ (Fig. 5). 


\section{Discussion}

To our knowledge, this is the first report for systematically studying the size, shape, and color of plastic debris distributed on the Marina Beach in Chennai, India. In this study, we also characterized the pattern of absorbed metal elements in the plastic materials and quantified the concentration of $\mathrm{As}, \mathrm{Cr}, \mathrm{Cu}$, and $\mathrm{Pb}$ on the plastics. As we know, the beach is a highly dynamic ecosystem, in which winds or waves always move sand and sediment [42]. The surrounding conditions of many beaches can lead to extensive changes in the composition of plastic debris. The higher number of beach plastic mainly comes from the presence of shops and hotels $[43,44]$. In monsoonal months, the usage of the beach is less due to the rainfall. However, we found a high abundance of plastics in November 2017-December 2017, which is consistent with the report by Jayasiri et al. [24]. Previous studies indicated that plastics on the beach were much higher during the rainy season because of the surface runoff, which led the plastics scraped from inland through rivers and to settle on the coastal line near to estuaries [45-47]. Barnes stated that the abundance of plastics was very strongly related to the human population [48].

\section{Petroleum-based plastics pollution in the Marina Beach}

The collected plastics were categorized into two principal categories in shape and color. The first type of plastic debris in this study was fiber. The predominance of plastic fibers in coastal sediments was consistent with most of the previous findings [49-52]. Claessens et al. revealed the second most common type of plastic debris in Weizhou Island was the plastic fiber [49]. Plastic fragments had different types on the shores of the Adriatic, but many of the residues were jagged fragments of larger plastic materials. The primary types of shape (by number) were fragments around $60.6 \%$, followed by $23.6 \%$ of film and $10.3 \%$ of fibers [34]. In our study, compared to other colors, the white plastic is the maximum abundant color. The percentage of white color plastic items has been detected in other studies, such as in Andaman Sea beach (Malaysia) 70\% [53] and Atlantic Ocean beach (Southwest England) 59\% [54]. 87.7\% of the collected plastic was also found to be white $[33,55,56]$. Small debris between the low tide and vegetation lines of 5-25 mm were collected [57-59]. As far as we know, only a few studies reported mesoplastic debris on the field $[13,60]$.

\section{Surface textures and validation of petroleum-based plastics}

The result of the SEM analysis showed the pits and fractures in the plastics debris were generated by the chemical weathering. Besides, the chemical and mechanical weathering of plastic contributed to the degradation of plastic particles. Our findings indicated that oxidative processes occurred in pits according to LDPE and PC. Small degradation patches in the PA showed the preferential site for continuous degradation, providing a favorable oxidation site. The adhering particles were the parts or pieces of other natural or synthetic substances grouped into larger components [61]. The cohesiveness of the surfaces results in adhesion to plastic particles. Analysis of petroleum-based plastics revealed that the adhering particles on PP and PC were prominent. The most common polymers found in the coastal area were the PET, PE, PS, and PP [38].

The FTIR spectroscopy provides a simple, effective, and non-destructive approach for the detection and identification of massive plastic polymers based on the well-known infrared absorbent database [62]. The $\mathrm{PE}$ and PP were found to dominate in the petroleumbased plastics in this study, because the PE and PP are the most produced plastic materials [30]. Commonly, the LDPE native bonds can be detected according to IR peaks at $1710 \mathrm{~cm}^{-1}, 1406 \mathrm{~cm}^{-1}, 1339 \mathrm{~cm}^{-1}, 1236 \mathrm{~cm}^{-1}$, $1089 \mathrm{~cm}^{-1}, 1009 \mathrm{~cm}^{-1}, 866$, and $717 \mathrm{~cm}^{-1}$ [63]. The spectral bands of PET at $1710 \mathrm{~cm}^{-1}, 1406 \mathrm{~cm}^{-1}, 1339 \mathrm{~cm}^{-1}$, 1236, 1089, and $1009 \mathrm{~cm}^{-1}, 866 \mathrm{~cm}^{-1}$, and $717 \mathrm{~cm}^{-1}$ were also previously described by Holland 2002 [64]. Our result was consistent with the report mentioned above. We also found the symmetric stretching of $\mathrm{CH}_{2}$ at $2928 \mathrm{~cm}^{-1}$ and the asymmetric stretching of $\mathrm{CH}_{2}$ groups within the polymer chain. The $\mathrm{C}=\mathrm{O}$ stretching was related to the spectrum at $1631.48 \mathrm{~cm}^{-1}$ and a combination of the $\mathrm{N}-\mathrm{H}$ band was at $1535 \mathrm{~cm}^{-1}$. These peaks have been reported as the PA native bonds [65]. A strong intensity of carbonyl bonds $\mathrm{C}=\mathrm{O}$ and an aromatic $(\mathrm{C}-\mathrm{H})$ at $2920 \mathrm{~cm}^{-1}$ and $1768.4 \mathrm{~cm}^{-1}$, indicating the $\mathrm{PC}$ native bonds [66].

The TGA-DSC analysis is a useful method for characterizing the physical properties of polymers, because it can be used for evaluating the melting point, crystallization, transition temperatures, and the changes of enthalpy and entropy [67]. In this study, the TGA-DSC curves were measured to detect endothermic reactions for all polymers. We hypothesized that the specific endothermic polymer peaks could be used to describe the petroleum-based plastic debris. The petroleum-based plastic debris (LDPE, PET, PA, and PC) showed the characteristic endothermic peaks $[66,68-70]$. The results of ATR-FTIR and TGA-DSC confirmed a $100 \%$ rate of petroleum-based plastic debris.

\section{The levels of trace metals in the petroleum-based plastics} Notably, the concentrations of metals in the plastics (Fig. 4) and metal concentration in fresh products 
(Additional file 1: Table S8) varied dramatically. The maximal levels occurred in plastic litter collected from sediments when compared to new products. Compared to the previously reported result, our collected plastic debris contained a higher amount of metals than sediments [20]. Plastics are the metal catcher and transporters to the sea [71], because it consists of organic polymer with high affinity to metal [17]. However, the absorption rate of metal to various plastic material is different due to the discrepancy in their physical nature and chemical properties [27, 72]. Metals can be accumulated in plastic debris from their surrounding ecosystem, which was confirmed by previous reports $[20,54,73]$. The plastics also can act as a vector for the transfer of trace metals into the food chain. Thus, birds, fish, mammals, and invertebrates may mobilize metals in their acidic digestive system, enzyme-rich pathways by mistakenly taking plastic material as food [12].

The content of As was high in the PA. The use of As in the manufacture formulations is now limited [74]. The high arsenic levels in the plastic debris may also be attributed to the age of manufactured objects resulting from the mesoplastic process or absorption [75]. In this study, the $\mathrm{Cu}$ concentrations in PET and PC were the lowest, but the sublethal dosage of $\mathrm{Cu}$ may also cause a significant reduction in the marine microalgae Tetraselmis chuii [8]. The level of $\mathrm{Cu}$ was low as reported in other studies [18]. The highest concentration of $\mathrm{Cu}$ in plastic fragments compared to virgin plastics was probably due to the higher surface area [76]. Cr has been detected in a similar level of magnitude in most plastics, except the PA. The plastic debris collected in the coastal areas had higher $\mathrm{Cr}$ content [17]. $\mathrm{Cr}$ is a ubiquitous ecosystem contaminant, which is toxic at ecologically relevant concentrations to the biota and humans. In this study, we found $\mathrm{Pb}$ in all-polymer debris, which can enter the food chain through biomagnification and bioaccumulation [77]. The significant difference of metal elements between plastic material was $p<0.05$, according to Tukey's HSD post hoc test and Kruskal-Wallis test. In the Persian Gulf, higher concentrations of metals $(\mathrm{Mn}, \mathrm{Al}, \mathrm{Fe}, \mathrm{Cd}, \mathrm{Cr}, \mathrm{Ni}, \mathrm{Pb}$, and $\mathrm{Cu})$ in the sediments than those in plastics have been reported by Dobaradaran et al. [39].

\section{Conclusions}

Taken together, this study revealed different petroleumbased plastics in the Marina Beach of Chennai, India. The Marina Beach is commonly used for recreation, and the monsoon also contributes to carrying different plastic fragments from the waste piles into the lakes, streams, and rivers, eventually to the beach. The main shapes of petroleum-based plastic debris were fragments, spheres, and fibers. In this study, the color of petroleum-based plastic debris was yellow, green, red, and blue. A total of 2275 petroleum-based plastic samples from the beach sediment were collected. The types of petroleum-based polymers, such as LDPE, PP, PET, PA, and PC were identified based on the ATR-FTIR and TGA-DSC analysis. For the mass determinations and type identification of plastic debris, the TGA-DSC provided an attractive option. LDPE, PP, PET, PA, and PC were quantified by the TGA-DSC. Furthermore, the ICP-MS analysis suggested that $\mathrm{As}, \mathrm{Cu}, \mathrm{Cr}$, and $\mathrm{Pb}$ were released into the marine environment, posing a severe threat to the organism in the aquatic environment.

\section{Supplementary information}

Supplementary information accompanies this paper at https://doi. org/10.1186/s12302-020-00388-5.

Additional file1: Table S1. The content of different elements in the plastic material. Table S2. Analysis of the plastic number differences between the categories (S1, S2, S3) with a confidence interval of 95\% using sites and Tukey (HSD). Table S3. Analysis of the Arsenic differences between the categories with a confidence interval of 95\% using plastics and Tukey (HSD). Table S4. Analysis of the Chromium differences between the categories with a confidence interval of 95\% using plastics and Tukey (HSD). Table S5. Analysis of the Copper differences between the categories with a confidence interval of 95\% using plastics and Tukey (HSD). Table S6. Analysis of the Lead differences between the categories with a confidence interval of 95\% using plastics and Tukey (HSD). Table S7. The principal component analysis of elements in the plastic debris. Table S8. Concentrations of metal carried by plastic debris in the environment. Fig. S1. Sample sites on the Marina Beach, Chennai, India. Fig. S2. The number and size of plastics in this study. Fig. S3. The metal concentration of different plastic debris collected from the Marina Beach, Chennai, India.

\section{Abbreviations}

As: Arsenic; Cr: Chromium; Cu: Copper; Pb: Lead; SEM: Scanning electron microscope; LDPE: Low-density polyethylene; PET: Polyethylene terephthalate; PP: Polypropylene; PA: Polyamide; PC: Polycarbonate; ICP-MS: Inductively coupled plasma mass spectrometry; ATR-FTIR: Fourier transform infrared spectroscopy-attenuated total reflectance; TGA-DSC: Thermogravimetry-differential scanning calorimetry.

\section{Acknowledgements}

The authors are thankful to Sathyabama Institute of Science and Technology, Jeppiaar Nagar, Chennai, India, for providing the necessary facilities.

\section{Authors' contributions}

TYS and WGL were involved in the experiments and manuscript writing. AS, FR.PV, JAD, and JGM were responsible for data analysis. DSP was involved in conceptualization, funding acquisition, project administration, and manuscript revision. All authors read and approved the final manuscript.

\section{Funding}

This work was supported by the CAS Team Project of the Belt and Road (to D.S.P.), Chongqing Key Program of Basic Research and Advanced Exploration Project (No. cstc2019jcyj-zdxmX0035 to D.S.P.), Three Hundred Leading Talents in Scientific and Technological Innovation Program of Chongqing (No. CSTCCXLJRC201714 to D.S.P.), Postdoctoral scholarship program of Henan Normal University (to T.Y Suman), and Program of China-Sri Lanka Joint Center for Water Technology Research and Demonstration by the Chinese Academy of Sciences (CAS)/China-Sri Lanka Joint Center for Education and Research by the CAS. 


\section{Availability of data and materials}

The datasets obtained and analyzed during the current study are available from the corresponding author on reasonable request.

\section{Ethics approval and consent to participate}

Not applicable.

\section{Consent for publication}

Not applicable.

\section{Competing interests}

The authors declare that they have no competing interests.

\section{Author details}

${ }^{1}$ College of Life Science, Henan Normal University, Xinxiang 453007, Henan, China. ${ }^{2}$ Chongqing Institute of Green and Intelligent Technology, Chinese Academy of Sciences, Chongqing 400714, China. ${ }^{3}$ Ecotoxicology Division, Centre for Ocean Research (DST-FIST SPONSERED), Sathyabama University, Chennai, Tamil Nadu 600119, India. ${ }^{4}$ Department of Chemical Engineering, Sathyabama Institute of Science and Technology, Chennai, Tamil Nadu 600119, India.

Received: 3 July 2020 Accepted: 12 August 2020

Published online: 27 August 2020

\section{References}

1. Andrady AL, Neal MA (2009) Applications and societal benefits of plastics. Philos Trans R Soc B Biol Sci 364:1977-1984

2. Andrady AL (2011) Microplastics in the marine environment. Mar Pollut Bull 62:1596-1605

3. Cole M, Lindeque P, Halsband C, Galloway TS (2011) Microplastics as contaminants in the marine environment: a review. Mar Pollut Bull 62:2588-2597

4. PlasticsEurope (2017) Plastics - The Facts 2017: an analysis of European latest plastics production, demand and waste data. PlasticsEurope, Wemmel

5. Gallagher A, Rees A, Rowe R, Stevens J, Wright P (2016) Microplastics in the Solent estuarine complex, UK: an initi" al assessment. Mar Pollut Bul 102:243-249

6. Maanan M, Saddik M, Maanan M, Chaibi M, Assobhei O, Zourarah B (2015) Environmental and ecological risk assessment of heavy metals in sediments of Nador lagoon. Morocco Ecol Indic 48:616-626

7. Turner A (2016) Heavy metals, metalloids and other hazardous elements in marine plastic litter. Mar Pollut Bull 111:136-142

8. Prata JC, Lavorante BR, Maria da Conceição BSM, Guilhermino L (2018) Influence of microplastics on the toxicity of the pharmaceuticals procainamide and doxycycline on the marine microalgae Tetraselmis chuii. Aquat Toxicol 197:143-152

9. Environmental Investigation Agency (2016) https://eia-international. org/ourwork/ecosystems-biodiversity/oceans/marine-plastic-pollution, Accessed 04 June 2018

10. Hopewell J, Dvorak R, Kosior E (2009) Plastic recycling: challenges and opportunities. Philos Trans Soc B. 364:2115-2126

11. Thompson RC, Swan SH, Moore CJ, Vom Saal FS (2009) Our plastic age. Philos Trans Biol Sci 364:1973-1976

12. Teuten EL, Saquing JM, Knappe DR, Barlaz MA, Jonsson S, Björn A, Rowland SJ, Thompson RC, Galloway TS, Yamashita R, Ochi D (2009) Transport and release of chemicals from plastics to the environment and to wildlife. Philos Trans R Soc B 364:2027-2045

13. Young AM, Elliott JA (2016) Characterization of microplastic and mesoplastic debris in sediments from Kamilo Beach and Kahuku Beach, Hawai'i. Mar Pollut Bull 113:477-482

14. Van Cauwenberghe L, Devriese L, Galgani F, Robbens J, Janssen CR (2015) Microplastics in sediments: a review of techniques, occurrence and effects. Mar Environ Res 111:5-17

15. Pasternak G, Zviely D, Ariel A, Spanier E, Ribic CA (2018) Message in a bottle-the story of floating plastic in the eastern Mediterranean sea. Waste Manag 77:67-77
16. Jambeck JR, Geyer R, Wilcox C, Siegler TR, Perryman M, Andrady A, Narayan R, Law KL (2015) Plastic waste inputs from land into the ocean. Science 347:768-771

17. Ashton K, Holmes L, Turner A (2010) Association of metals with plastic production pellets in the marine environment. Mar Pollut Bull 60:2050-2055

18. Holmes LA, Turner A, Thompson RC (2012) Adsorption of trace metals to plastic resin pellets in the marine environment. Environ Pollut 160:42-48

19. Mato Y, Isobe T, Takada H, Kanehiro H, Ohtake C, Kaminuma T (2001) Plastic resin pellets as a transport medium for toxic chemicals in the marine environment. Environ Sci 35:318-324

20. Rochman CM, Hentschel BT (2014) Long-term sorption of metals is similar among plastic types: implications for plastic debris in aquatic environments. PLoS ONE 9:85433

21. Swamidurai S (2014) Factors affecting urban land value in Indian citiesChennai city as a case study. Int J Res Sci Innovation I(lii):31-34

22. Ziccardi LM, Edgington A, Hentz K, Kulacki KJ, Kane Driscoll S (2016) Microplastics as vectors for bioaccumulation of hydrophobic organic chemicals in the marine environment: a state-of-the-science review. Environ Toxicol Chem 35:1667-1676

23. Browne MA, Niven SJ, Galloway TS, Rowland SJ, Thompson RC (2013) Microplastic moves pollutants and additives to worms, reducing functions linked to health and biodiversity. Curr Biol 23:2388-2392

24. Jayasiri HB, Purushothaman CS, Vennila A (2013) Quantitative analysis of plastic debris on recreational beaches in Mumbai, India. Mar Pollut Bull. 77:107-112

25. Reddy MS, Basha S, Adimurthy S, Ramachandraiah G (2006) Description of the small plastics fragments in marine sediments along the AlangSosiya ship-breaking yard, India. Estuar Coast Shelf Sci. 68:656-660

26. Sruthy S, Ramasamy EV (2017) Microplastic pollution in Vembanad Lake, Kerala, India: the first report of microplastics in lake and estuarine sediments in India. Environ Pollut 222:315-322

27. Karapanagioti HK, Klontza I (2008) Testing phenanthrene distribution properties of virgin plastic pellets and plastic eroded pellets found on Lesvos island beaches (Greece). Mar Environ Res 65:283-290

28. Turner A (2010) Marine pollution from antifouling paint particles. Mar Pollut Bull 60:159-171

29. Link T (2014) A report on impact of e-waste recycling on water and soil. New Delhi, India (Book)

30. Pietrelli L, Poeta G, Battisti C, Sighicelli M (2017) Characterization of plastic beach debris finalized to its removal: a proposal for a recycling scheme. Environ Sci Pollut Res 24:16536-16542

31. Pradhan U, Naik S, Begum M, Kumar SS, Panda US, Mishra P, Murthy MV (2018) Marine litter: post-flood nuisance for Chennai beaches. Curr Sci 115:1454-1455

32. Kumar A, Sivakumar R, Reddy YSR, Raja B, Nishanth T, Revanth V (2016) Preliminary study on marine debris pollution along Marina beach, Chennai, India. Reg Stud Mar Sci 5:35-40

33. Heo NW, Hong SH, Han GM, Hong S, Lee J, Song YK, Jang M, Shim WJ (2013) Distribution of small plastic debris in cross-section and high strandline on Heungnam beach, South Korea. Ocean Sci J 48:225-233

34. Munari C, Scoponi M, Mistri M (2017) Plastic debris in the Mediterranean Sea: types, occurrence and distribution along Adriatic shorelines. Waste Manag 67:385-391

35. Li J, Zhang H, Zhang K, Yang R, Li R, Li Y (2018) Characterization, source, and retention of microplastic in sandy beaches and mangrove wetlands of the Qinzhou Bay, China. Mar Pollut Bull 136:401-406

36. Wang J, Peng J, Tan Z, Gao Y, Zhan Z, Chen Q, Cai L (2017) Microplastics in the surface sediments from the Beijiang River littoral zone: composition, abundance, surface textures and interaction with heavy metals. Chemosphere 171:248-258

37. Browne MA, Galloway TS, Thompson RC (2010) Spatial patterns of plastic debris along estuarine shorelines. Environ Sci Technol 44:3404-3409

38. Hidalgo-ruz V, Gutow L, Thompson RC, Thiel M (2012) Microplastics in the marine environment: a review of the methods used for identification and quantification. Environ Sci Technol 46:3060-3075

39. Dobaradaran S, Schmidt TC, Nabipour I, Khajeahmadi N, Tajbakhsh S, Saeedi R, Mohammadi MJ, Keshtkar M, Khorsand M, Ghasemi FF (2018) Characterization of plastic debris and association of metals with 
microplastics in coastline sediment along the Persian Gulf. Waste Manag. 78:649-658

40. Van A, Rochman CM, Flores EM, Hill KL, Vargas E, Vargas SA, Hoh E (2012) Persistent organic pollutants in plastic marine debris found on beaches in San Diego, California. Chemosphere 86:258-263

41. Yoganandham ST, Raguraman V, Muniswamy G, Sathyamoorthy G, Renuka RR, Chidambaram J, Rajendran T, Chandrasekaran K, Ravindranath RRS (2019) Mineral and trace metal concentrations in seaweeds by microwave-assisted digestion method followed by quadrupole inductively coupled plasma mass spectrometry. Biol Trace Elem Res 187:579-585

42. McLachlan A, Brown AC (2006) The ecology of sandy shores. Academic Press, Burlington, Massachusetts

43. Cai L, Wang J, Peng J, Wu Z, Tan X (2018) Observation of the degradation of three types of plastic pellets exposed to UV irradiation in three different environments. Sci Total Environ. 628:740-747

44. Kunz A, Walther BA, Löwemark L, Lee YC (2016) Distribution and quantity of microplastic on sandy beaches along the northern coast of Taiwan. Mar Pollut Bull 111:126-135

45. Brennan E, Wilcox C, Hardesty BD (2018) Connecting flux, deposition and resuspension in coastal debris surveys. Sci Total Environ 644:1019-1026

46. Cheung PK, Cheung LTO, Fok L (2016) Seasonal variation in the abundance of marine plastic debris in the estuary of a subtropical macro-scale drainage basin in South China. Sci Total Environ 562:658-665

47. Wessel C, Swanson K, Weatherall T, Cebrian J (2019) Accumulation and distribution of marine debris on barrier islands across the northern Gulf of Mexico. Mar Pollut Bull 139:14-22

48. Barnes DKA (2005) Remote islands reveal rapid rise of Southern Hemisphere sea debris. Dir Sci 5:915-921

49. Claessens M, Meester SD, Landuyt LV, Clerck KD, Janssen CR (2011) Occurrence and distribution of microplastics in marine sediments along the Belgian coast. Mar Pollut Bull 62:2199-2204

50. Gago J, Carretero O, Filgueiras AV, Vinas L (2018) Synthetic microfibers in the marine environment: a review on their occurrence in seawater and sediments. Mar Pollut Bull 127:365-376

51. Guerranti C, Cannas S, Scopetani C, Fastelli P, Cincinelli A, Renzi M (2017) Plastic litter in aquatic environments of maremma regional park (Tyrrhenian sea, Italy): contribution by the ombrone river and levels in marine sediments. Mar Pollut Bull 117:366-370

52. Maes T, Van der Meulen MD, Devriese LI, Leslie HA, Huvet A, Frere L, Robbens J, Vethaak AD (2017) Microplastics baseline surveys at the water surface and in sediments of the north-East Atlantic. Front Mar, Sci, p 4

53. Ismail A, Adilah N, Nurulhudha M (2009) Plastic pellets along Kuala Selangor-Sepang coastline. Malays Appl Biol. 38:85-88

54. Holmes LA (2013) Interactions of trace metals with plastic production pellets in the marine environment. (Research Thesis). http://hdl.handl e.net/10026.1/1593

55. Morris RJ (1980) Plastic debris in the surface waters of the South Atlantic. Mar Pollut Bull 11:164-166

56. Veerasingam S, Saha M, Suneel V, Vethamony P, Rodrigues AC, Bhattacharyya S, Naik BG (2016) Characteristics, seasonal distribution and surface degradation features of microplastic pellets along the Goa coast, India. Chemosphere 159:496-505

57. Cheshire AC, Adler E, Barbiere J, Cohen Y, Evans S. Jarayabh S, Jeftic L,Jung RT, Kinsey S, Kusui ET, Lavine I, Manyara P, Oosterbaan L, Pereira MA, Sheavly S, Tkalin A, Varadarajan S, Wenneker B, Westphalen G (2009) UNEP/IOC Guidelines on Survey and Monitoring of Marine Litter. UNEP Regional Seas Reports and Studies, No. 186; IOC Technical Series, No. 83 xii. pp 120

58. Galgani F, Hanke G, Maes T (2015) Global distribution, composition and abundance of marine litter. Marine anthropogenic litter. Springer, Cham, pp 29-56

59. Lee J, Hong S, Song YK, Hong SH, Jang YC, Jang M, Heo NW, Han GM, Lee MJ, Kang D, Shim WJ (2013) Relationships among the abundances of plastic debris in different size classes on beaches in South Korea. Mar Pollut Bull 77:349-354

60. Jabeen K, Su L, Li J, Yang D, Tong C, Mu J, Shi H (2017) Microplastics and mesoplastics in fish from coastal and fresh waters of China. Environ Pollut 221:141-149
61. Mahaney WC (2002) Atlas of sand grain surface textures and applications. Oxford University Press, Oxford

62. Asefnejad A, Khorasani MT, Behnamghader A, Farsadzadeh B, Bonakdar S (2011) Manufacturing of biodegradable polyurethane scaffolds based on polycaprolactone using a phase separation method: physical properties and in vitro assay. Int J Nanomedicine 6:2375

63. Gulmine JV, Janissek PR, Heise HM, Akcelrud L (2002) Polyethylene characterization by FTIR. Polym Test. 21:557-563

64. Holland BJ (2002) Polymer 43:1835

65. Elnagar K, Abou Elmaaty T, Raouf S (2014) Dyeing of polyester and polyamide synthetic fabrics with natural dyes using ecofriendly technique. J Text

66. Owais A et al (2016) Surface and wetting characteristics of textured bisphenol-a based polycarbonate surfaces: acetone-induced crystallization texturing methods. J Appl Polym Sci 133:1-10

67. Baltes L, Costiuc L, Patachia S, Tierean M (2019) Differential scanning calorimetry - a powerful tool for the determination of morphological features of the recycled polypropylene. J Thermal Anal Calorim 138(4):2399-2408

68. Apaydin K, Laachachi A, Ball V, Jimenez M, Bourbigot S, Ruch D (2015) Layer-by-layer deposition of $\mathrm{TiO}_{2}$-filled intumescent coating and its effect on the flame retardancy of polyamide and polyester fabrics. Colloids Surf A Physicochem Eng Asp. 469:1-10

69. Cai Y, Ke H, Zhang T, Dong J, Qiao H, Wang H, Xu Z, Wei Q, Zhao Y, Fong H (2011) Preparation, morphology and properties of electrospun lauric acid/PET form-stable phase change ultrafine composite fibers. Polym Polym Compos 19:773

70. Chowdhury SR, Sabharwal S (2011) Molecular-scale design of a high performance organic-inorganic hybrid with the help of gamma radiation. J Mater Chem A Mater. 21:6999-7006

71. Vedolin MC, Teophilo CYS, Turra A, Figueira RCL (2018) Spatial variability in the concentrations of metals in beached microplastics. Mar Pollut Bull 129:487-493

72. Teuten EL, Rowland SJ, Galloway TS, Thompson RC (2007) Potential for plastics to transport hydrophobic contaminants. Environ Sci Technol 41:7759-7764

73. Holmes LA, Turner A, Thompson RC (2014) Interactions between trace metals and plastic production pellets under estuarine conditions. Mar Chem 167:25-32

74. Hansen E, Nilsson, NH, Lithner D, Lassen C (2010) Hazardous substances in plastic materials, COWI and the Danish technological institute on behalf of the Norwegian Climate and Pollution Agency. In Oslo

75. Prunier J, Maurice L, Perez E, Gigault J, Wickmann ACP, Davranche M, Ter Halle A (2019) Trace metals in polyethylene debris from the North Atlantic subtropical gyre. Environ Pollut 245:371-379

76. Brennecke D, Duarte B, Paiva F, Caçador I, Canning-Clode J (2016) Microplastics as vector for heavy metal contamination from the marine environment. Estuar Coast Shelf Sci 178:189-195

77. Tong YP, Zhu ZP, Hao X, He L, He WB, Chen JM (2016) The study of lead content distribution in Chinese seafood and its oral bioavailability in mice. Environ Sci Pollut Res 23:1714-1721

\section{Publisher's Note}

Springer Nature remains neutral with regard to jurisdictional claims in published maps and institutional affiliations. 